\title{
A Conceptual Framework of Supply Chain Integration for Competitive Advantage
}

\author{
Venkat Ramesh ${ }^{*}$, Y Vijaya Kumar ${ }^{\dagger}$ and Sindhu ${ }^{\ddagger}$
}

\section{Abstract:}

Growth as one of the key preconditions to survive in the market is forcing companies to compete on international markets and at the same time defend domestic market share from international competitors. The result of that is increased complexity of supply chains, pressure to decrease cost and improve service level. To cope with the complexity and increased customer requirements, active management of the supply chain is a prerequisite. As supply chain is a network of three or more entities directly involved in the upstream and downstream flows of products, services, finance and information from a source to a customer, management of it is a complex task.

There is significant evidence from literature that the effective implementation of integrated supply chain management (SCM) has the potential to generate significant improvements in the performance of firms. The higher levels of SCM practice can lead to enhanced competitive advantage and improved organizational

\footnotetext{
"Research Scholar, School of Management Studies, Jawaharlal Nehru Technological University, Hyderabad (JNTUH), India; avenkat_ramesh@yahoo.co.in tPrincipal, ShirdiSai Engineering College, Anekal, Bangalore, India; kumar_vy@rediffmail.com ‡Associate Professor, School of Management Studies, , (JNTUH), India; sindhu999@jntuh.ac.in
} 
performance. In order to achieve efficient supply chain integration for the processes or activities, the organizations should recognize and understand all the integration challenges of supply chain.

The aim of this paper is to investigate previous research studying the relationship between supply chain integration and performance and understand the importance of supply chain integration for competitive positioning of organization, to address the challenges encountered in integration of supply chain, and to propose a conceptual framework to reap the potential benefits of effective supply chain integration.

Keywords: Supply Chain Integration, Challenges, Performance, Strategic Management

\section{Introduction}

Since its introduction in the early 1980s, supply chain management (SCM) has attracted a lot of attention in both business and academic circles. Recent years have seen a proliferation of literature with its origins in a range of academic disciplines and industry sectors. This has prompted scholars to classify the literature in various ways. For example, Tan (2001) illustrates the evolution of SCM from both purchasing and supply perspective, as well as a transportation and logistics perspective. However, one theme that is a characteristic of much of the scholarly work in the field is that of integration.

Many organizations today are forced to increase their global market share in order to survive and sustain growth objectives. Long term competitiveness therefore depends on how well the company meets customer preferences in terms of service, cost, quality and flexibility by designing the supply chain which will be more effective and efficient than the competitors. Optimisation of this equilibrium is a constant challenge for the companies which are part of the supply chain network. To be able to optimize this equilibrium, many strategic decisions must be taken and many activities to be coordinated. This requires careful management and design of the supply chain. The design of the supply chain represents a distinct means by which companies innovate, 
differentiate and create value (Fung, 2004). The challenge of supply chain design and management is in the capability to design and assemble assets, organizations, skills and competences. It encompasses the team, partners, products \&processes.

According to Mentzer et al., (2001) a supply chain is defined as "A set of three or more entities (organizations or individuals) directly involved in the upstream and downstream flows of products, services, finances and / or information from a source to a customer".

Supply Chain Integration (SCI), has become a prominent issue during the last decade. In recent years, there has been a great deal of empirical evidence to show that successful supply-chain integration can improve a firm's performance and competitive advantage (Weingarten et. al., 2010). Supply chain management seeks to enhance competitive performance by closely integrating the internal cross-functions within a company and effectively linking them with the external operations of suppliers, customers and other channel members to be successful (Kim, 2006). This means that a firm pursuing SCM practices needs to pay attention to supply chain integration and its implementation (Hussein \& Nassar, 2010).

Integration in this context refers to the extent to which various supply chain activities and processes work together in as seamless manner as possible. It has long been recognised that traditionally managed businesses and supply chains, often characterized by high levels of fragmentation, have failed to achieve their true potential in terms of profitability and meeting customer expectations. Supply chain integration (SCI) is, to a great extent, concerned with the development of more integrated approaches that hold out the prospect of eliminating many of the inefficiencies directly attributable to supply chain fragmentation.

\section{Literature Review}

\subsection{Supply Chain Management}

The paradigm of "Supply Chain Management" has gone through huge developments globally. SCM seeks to enhance competitive performance by closely integrating the internal cross-functions 
within a company and effectively linking them with the external operations of suppliers, customers and other channel members to be successful (Hadfield 1998; Kim 2006). The objective of supply chain management is to maximize the overall value generated rather than profit generation (Otchere et. al., 2013). Although the importance of supply chain relations is widely acknowledged, seamless coordination is rarely achieved in practice coupled with several challenges (Hussain \& Nassar, 2010; Otchere et. al, 2013).

\subsection{Supply Chain Integration}

Supply chain integration is defined as "the extent to which all activities within an organization and the activities of its suppliers, customers and other supply chain members are integrated together", (Narasimhan et. al., 1998). SCM has three independent variables in its original scale they are: internal, suppliers and customer integrations. Some also considers integration in two levels: internal integration and external integration (Tutuncu \& Kucukusta, 2008). Stevens (1989) classifies supply chain integration into three levels, from functional integration to internal integration and to external integration. However, this study focuses only on internal and external integration, because functional integration is a pre-requisite for all firms to implement and achieve internal integration (Otchere et. al., 2013). The dominant belief is that supply chain integration is a useful approach to improve various measures of firm performance (Wiengarten et. al 2010; Otchere et. al., 2013). The basis of integration can therefore be characterized by cooperation, collaboration, information sharing, trust, partnerships, shared technology and a fundamental shift away from managing individual functional processes to managing integrated chains of processes (Kahn 1998; Pagell 2004).

\subsection{Internal Integration}

Internal integration involves cross functional teams that may bring together a carefully selected array of specialists who share information and make product, process and manufacturing decisions, jointly and simultaneously (Koufteros, Vonderembse \& Jayaram, 2005; Otchere et. al., 2013). Internal integration is defined as a process of inter-functional interaction, collaboration, coordination, communication and cooperation that bring functional 
areas together into a cohesive organization (Kahn, 1998; Flynn et. al., 2010; Zhao et. al., 2011).

Furthermore, supply chain partners who exchange information regularly are able to work as a single entity and can understand the needs of the end customer better and hence can respond to market change quicker (Stein and Sweat, 1998). A prerequisite for successful SCM is internal integration (Lambert, Cooper \& Pagh, 1998). Also companies with a low internal integration strategy will achieve low level of external integration and companies implementing the full internal integration strategy will have the highest levels of external integration (Stevens, 1989; Gimenez \& Ventura, 2005). Generally it is believed that firms achieve a relatively high degree of internal integration before they attempt to develop a higher degree of external integration (Gimenez and Ventura, 2005). Internal integration can be accomplished through automation and standardization of each internal function(Bowersox, 1989).

\subsection{External Integration}

As the competitive environment is becoming increasingly challenging, firms are undertaking efforts to compete along multiple fronts. However, many firms find it difficult to compete in the market by relying on their internal resources and competencies alone. They have turned to collaborate with their customers and suppliers to obtain information and complementary resources, which they can deploy to build competitive advantage. External supply chain integration reveals two major areas of emphasis. They are Customer Integration (CI) and Supplier Integration (SI). Supplier integration also called "backward" integration (Frohlich and Westbrook, 2001) refers to the process of interaction and collaboration between an organization and its suppliers to ensure an effective flow of supplies (Zhao et. al., 2011). Customer integration, also called "forward" integration (Frohlich\& Westbrook, 2001) refers to the process of interaction and collaboration between an organization and its customers to ensure an effective flow of products and / or services to customers (Zhao et. al., 2002). Customer integration involves sharing demand information, help the manufacturer to understand customer needs 
and to forecast better customer demand as well as collaborative involvement of customers with respect to product design, provision of better quality products at lower cost and more flexibility in responding to customer demand (Flynn et. al., 2010).

\subsection{Challenges in Integrating Supply Chain}

Supply chain management executives face unique challenges, with respect to integrating supply chain specific strategies with the overall corporate business strategy; hence seamless coordination is rarely achieved in practice (Hussain \& Nassar, 2010). Most SCI related problems originate, either from uncertainties or an inability to co-ordinate several activities and partners. Simultaneously, customers have become more discerning and are demanding better quality products, higher levels of service and reduced prices, (Sweeney, 2011). Unfortunately, obtaining supply chain integration has been an elusive quest for many companies (Fawcett \& Magnan, 2002). Studies have revealed that, unlike other endeavors that a firm undertakes, there is no blueprint for integration and aggregate measure of overall supply chain performance from which a firm could compare performance with other industry members. After extensive review of different perspectives from previous publications on supply chain integration challenges, they tried to introduce a comprehensive source, which will contain all the challenges mentioned in the literature in one paper as follows: Transaction costs, strategy and planning, customer order management, logistics management, manage operation and flexibility, setting up standards of trade, procurement management, enterprise integration, application integration, extranet adaption challenges, business process integration, culture and change, supplier competence requirements, globalization, data and information integration (Hussain \& Nassar, 2010).

The implementation process should start from functional integration through internal integration to external integration (Supplier and Customer). Some authors argue that performance improvements are not assured with just one aspect of supply chain integration, they have proposed that implementing integration both upstream, operations and downstream is better than concentrating the firm's efforts on integrating customers or 
suppliers (Frohlich \& Westbrook, 2001). Furthermore, it is confirmed that, the best integration strategy must involve “complete integration"(Kannan \& Tan, 2010).

\section{Need for Integrated Supply Chain}

Supply chain management has become today's most important concept for competitive advantage because it enables companies organized along a supply chain to exploit the new realities transforming the marketplace.

Research conducted by Mercer Management Consulting reveals that organizations with the best supply chains typically excel in certain pivotal performance areas. Specifically, they outperform their counterparts along such key metrics as reducing operating costs, improving asset productivity, and compressing order-cycle time.

The most commonly reported bottom-line benefits center on reduced costs in such areas as inventory management, transportation, and warehousing and packaging, improved service through techniques such as time-based delivery and make-to-order, and enhanced revenues, which result from such supply chain related achievements as higher product availability and more customized products.

\section{Objectives of the study:}

The objective of supply chain management is to contribute to improvements in the company's bottom line or profitability. To achieve this objective, companies should coordinate and integrate their activities with other companies.

\section{Objectives of this study:}

- To review literature and understand how supply chain integration is achieved internally and externally.

- To identify challenges encountered in supply chain integration and how they are overcome. 
- To determine the potential benefits resulting from integrated supply chain.

- To propose a conceptual framework for integration of supply chain within and across the enterprise.

\section{Strategic Supply Chain Management}

The strategic supply chain continues to be adopted by organizations as the medium for creating and sustaining a competitive advantage (Ireland \& Webb, 2007). Such a displacement is understandable considering the potential benefits of successful supply chain management. These benefits include inventory reduction, improved delivery service and shorter product development cycles. Despite these enticing benefits, organizations who partner in strategic supply chains continue to encounter barriers. These barriers exist at multiple levels of organization: the organizational, intra-organizational, interorganizational levels.

Strategic supply chains are supply chains were the "members are strategically, operationally and technologically integrated" and are anticipated for long-term stable relationships with the ability to change to the demands of the environment (Hult et. al., 2004).

Typically, the contingency model is driven by dynamic technological innovation, management skills across department and organizational functions and integration vertically and horizontally across industry (Stonebraker \& Afifi, 2004). These drivers can be considered driving forces (Lewin, 1951). Although these drivers push for supply chain collaboration there are barriers or resisting forces (Lewin, 1951). Such resisting forces include lack of member support, inadequate measurement and information systems and organizational culture. Nevertheless, organizations are not powerless in terms of choices or their ability in attempting to overcome these barriers. Strategic supply chain partners can create and implement initiatives that bridge the gap between a supply chain and a strategic supply chain. Some of these bridges include people empowerment, information and alliance design. Thus, strategic supply chains can create value contingent on their ability to overcome resisting forces through various mechanisms. Figure 1 
shows a contingency framework for understanding SCM implementation.

\section{Forces Driving SC} Collaboration

More Demanding

Customers

-Greater competitive

intensity

-Shifting channel power

-Electronic globalization

-Tighter alliance

relationships

-Compressed product

cycles

-Continued merger

activity

-Need for better

information

-New information

technologies

-Shifting competitive

focus i.e. companies to

supply chains.

\section{Bridges to effective SCM}

Alignment

Mechanisms

-Cross-Functional

Process Change

-Performance

Measurement

\section{SCI}

-Information Systems

-Alliance Design

-People Empowerment

\section{Benefits of Effective SCM}

\begin{tabular}{|l|l|}
\multicolumn{1}{c}{ SCM } \\
Unique products \& \\
services \\
-Faster R\&D cycle times \\
-Superior Quality \\
-Cost competitiveness \\
-Shorter order cycles \\
-Flexible customer \\
response \\
-Enhanced delivery \\
performance \\
-Better asset management \\
-Increased cash-to-cash \\
velocity \\
-Superior channel \\
relationships \\
\hline
\end{tabular}

Implementation Barriers to Effective SCM

-Lack of top management support

-Non-aligned strategic and operating philosophies

-Inability or unwillingness to share information

-Lack of trust among supply chain members

-An unwillingness to share risks and rewards

-Inflexible organizational systems and processes

-Cross-functional conflicts

-Inconsistent / Inadequate performance measures

-Resistance to change

-Lack of training for new mindsets and skills

Fig 1. A contingency Framework for understanding supply chain implementation

\section{Supply Chain Orientation}

Mentzer (2002) defines supply chain orientation as "Recognition by an organization of the systemic, strategic implications of the tactical activities involved in managing the various flows in a supply chain". The implementation of supply chain orientation requires several companies in the supply chain to utilize supply chain 
processes to realize the set of management activities as defined in figure 2 .

\begin{tabular}{|c|c|c|}
\hline Supply Chain & Supply Chain & \\
\hline & Three or more & Consequences \\
\hline $\begin{array}{l}\text { Systemic View } \\
\text { Strategic View }\end{array}$ & $\begin{array}{l}\text { contiguous companies } \\
\text { with a supply chain }\end{array}$ & Lower costs \\
\hline 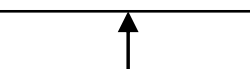 & orientation. & $\begin{array}{l}\text { Improved customer } \\
\text { value \& satisfaction }\end{array}$ \\
\hline Single Company & & Competitive \\
\hline Reasons & Shared risks and & advantage \\
\hline $\begin{array}{l}\text { Willingness to } \\
\text { address: }\end{array}$ & rewards & \\
\hline Trust & Cooperation & \\
\hline Commitment & & \\
\hline Interdependence & $\begin{array}{l}\text { Similar customer service } \\
\text { goals and focus }\end{array}$ & \\
\hline Organisational & goals ana rocus & \\
\hline Compatibility & Integration of key & \\
\hline Vision & processes & \\
\hline Key processes & & \\
\hline Leader & Long term relationships & \\
\hline $\begin{array}{l}\text { Top management } \\
\text { support }\end{array}$ & $\begin{array}{l}\text { Inter functional } \\
\text { coordination }\end{array}$ & \\
\hline
\end{tabular}

Fig 2. Supply Chain Management - Reasons and Consequences

Source: Mentzer, 2002.

From reviewing the literature on supply chain management, we can conclude that it is very difficult to make one universal definition of supply chain management, as standards regarding processes as well as terminology do not exist. However it is also common in most of the author's definitions, that company focusing on supply chain management can achieve competitive advantage by lowering costs and simultaneously improving customer satisfaction. They achieve that by optimizing the complete value chain, seeking value creation opportunities by closer cooperation with their partners in the supply chain. This also requires advanced collaboration models (sharing information about demand on the market, integration of key processes and therefore long term relationships, as well as inter-functional coordination). On the other hand, it is crucial for successful cooperation that all parties 
involved in an integrated supply chain management have high level of trust among them. They need to be committed to a similar overall vision, have a compatible organizations, key processes and most importantly top management support.

\section{Drivers of Supply Chain Development}

In today's global economy, companies face increasing pressure to reduce costs while maintaining production and quality levels to deliver results. In order to achieve these goals, companies must successfully overcome a number of challenges. As Meakem (2003) points out, free market economies and new technologies are creating new supply and demand markets around the world. Handfield (2002) summarises drivers into:

- Ever increasing customer demand in terms of product and service cost, quality, delivery, technology and cycle time brought about by global competition.

- The emergence and greater acceptance of higher-order cooperative inter-organizational relationships.

- The information revolution.

The consequence of this development is that companies are putting more and more effort into developing new ways to increase competitiveness on the market in terms of more efficient and effective supply chain management.

\section{Key Components of Successful Supply Chain Management}

The level of supply chain maturity drives both supply chain and financial performance. However, companies must select supply chain practices that are most aligned with their supply chain strategy and overall business. Pittiglio Rabin Todd \&McGrath(PRTM) has developed the framework for successful supply chain management based on five core disciplines (Cohen et al., 2004) as shown in Figure 3. 
1. View your supply chain as a strategic asset

Design the supply chain around a defined Basis of competition to enable the overall strategy
2. Develop an end-to-end process architecture

Develop integrated supply chain processes \& systems that interface business efficiently with the rest of the enterprise.

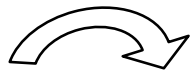

5. Use metrics to drive business success

Use metrics to measure the health of each core

Supply chain process and identify problem areas.

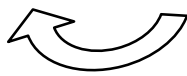

4. Build the right collaborative model

Understand core competences and choose partners to maximize focus on profitability
3.Design your organization for performance

Develop and maintain organizational structure \& skills to define and manage the supply chain of the future.

Fig 3. Five Core Disciplines for strategic supply chain management

Source: Cohen et al., 2004.

The view of supply chain as strategic asset is related to business planning. Organizational planning is connected to developing end to end processes, designing organization and building the right collaborative model, while metrics is related to controlling. Leadership is, on the other hand, one of key components of successful implementation of those plans and is therefore the key skill of managers.

\section{Levels of Supply Chain Maturity}

To evaluate how good companies are in using emerging supply chain practices and how successful they are in choosing the right ones, Performance Management Group (PMG) and consulting company, PRTM jointly developed the supply chain maturity model (Figure 4). The model is based on a combination of bench marking, experience and field knowledge of current and emerging practices across different industries over the past five years.

The model defines four stages of operational capability. Companies almost always progress through the stages in sequence, by building on the practices they have solidly established at each stage. 
Attempts to advance without a base of firmly established practices are rarely successful (Cohen, 2004).

The model also evaluates the extent to which information technology enables richer practices and cross-enterprise integration in supply chain management.

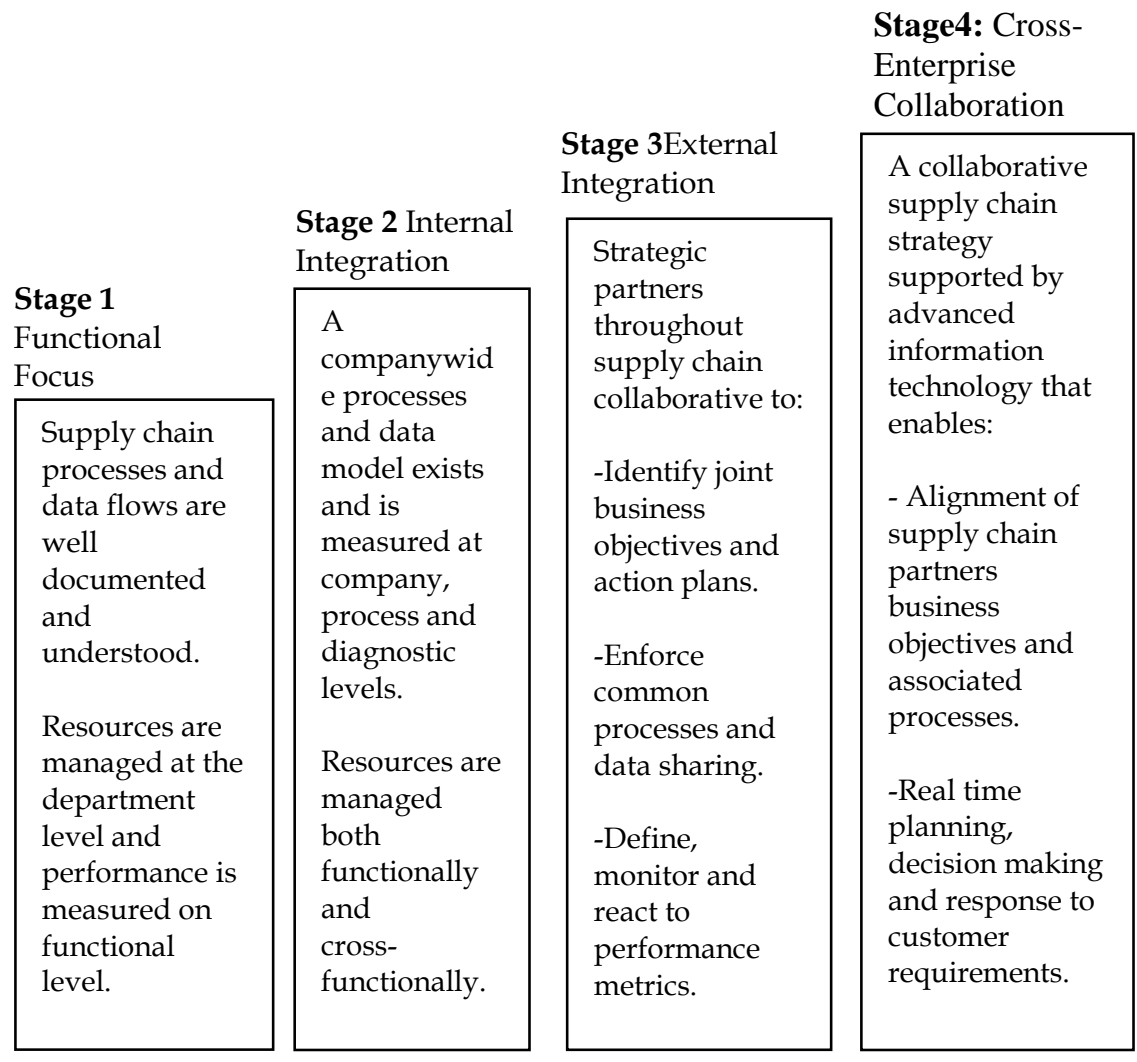

(Supply chain performance Vs Operational Capability)

Fig 4: Levels of supply chain maturity

Source: Cohen, 2004.

\section{Most Common Benefits, Barriers and Bridges to Successful Supply Chain Management}

The centre of Advanced Purchasing Studies (Fawcett et. al., 2002) made a research of what the most common benefits, barriers and bridges when implementing advanced supply chain practices are. The results of the survey shows that most common benefits are 
related to increased responsiveness of the companies (external and internal), lower cost, better quality and closer relationships with key partners.

The main barriers presented in the table 1 can be summarized into management and organizational issues within the organization and with external partners. The most common bridges that can help overcome barriers are: senior and functional management support, open and honest information sharing, good measurement systems, process documentation, education and training, use of supply chain advisory council.

Table 1: Benefits, Barriers and Bridges to Supply Chain Integration

\begin{tabular}{|l|l|l|}
\hline Benefits & Barriers & Bridges \\
\hline $\begin{array}{l}\text { Increased customer } \\
\text { responsiveness }\end{array}$ & $\begin{array}{l}\text { Inadequate } \\
\text { information sharing }\end{array}$ & $\begin{array}{l}\text { Senior \& functional } \\
\text { managerial support }\end{array}$ \\
\hline $\begin{array}{l}\text { More consistent on- } \\
\text { time delivery }\end{array}$ & $\begin{array}{l}\text { Poor / conflicting } \\
\text { measurement }\end{array}$ & $\begin{array}{l}\text { Open and honest } \\
\text { information sharing }\end{array}$ \\
\hline $\begin{array}{l}\text { Shorter order } \\
\text { fulfillment lead } \\
\text { times }\end{array}$ & $\begin{array}{l}\text { Inconsistent } \\
\text { operating goals }\end{array}$ & $\begin{array}{l}\text { Accurate and } \\
\text { comprehensive measures }\end{array}$ \\
\hline $\begin{array}{l}\text { Reduced inventory } \\
\text { costs }\end{array}$ & $\begin{array}{l}\text { Organizational } \\
\text { culture \& structure }\end{array}$ & $\begin{array}{l}\text { Trust bases, synergistic } \\
\text { alliances }\end{array}$ \\
\hline $\begin{array}{l}\text { Better asset } \\
\text { utilization }\end{array}$ & $\begin{array}{l}\text { Resistance to change } \\
\text { - lack of trust }\end{array}$ & $\begin{array}{l}\text { Supply chain alignment \& } \\
\text { rationalization }\end{array}$ \\
\hline $\begin{array}{l}\text { Lower costs of } \\
\text { purchased items }\end{array}$ & $\begin{array}{l}\text { Poor alliance } \\
\text { management } \\
\text { practices }\end{array}$ & $\begin{array}{l}\text { Cross-experienced } \\
\text { managers }\end{array}$ \\
\hline $\begin{array}{l}\text { Higher product } \\
\text { quality }\end{array}$ & $\begin{array}{l}\text { Lack of SC vision } \\
\text { (understanding) }\end{array}$ & $\begin{array}{l}\text { Process documentation \& } \\
\text { ownership }\end{array}$ \\
\hline $\begin{array}{l}\text { Ability to handle } \\
\text { unexpected events }\end{array}$ & $\begin{array}{l}\text { Lack of managerial } \\
\text { commitment }\end{array}$ & $\begin{array}{l}\text { Supply chain education } \\
\text { and training }\end{array}$ \\
\hline $\begin{array}{l}\text { Faster product } \\
\text { innovation }\end{array}$ & $\begin{array}{l}\text { Constrained } \\
\text { resources }\end{array}$ & $\begin{array}{l}\text { Use of supply chain } \\
\text { advisory councils }\end{array}$ \\
\hline $\begin{array}{l}\text { Preferred \& } \\
\text { tailored } \\
\text { relationships }\end{array}$ & $\begin{array}{l}\text { No employee } \\
\text { passion / } \\
\text { empowerment }\end{array}$ & $\begin{array}{l}\text { Effective use of pilot } \\
\text { projects }\end{array}$ \\
\hline
\end{tabular}

\section{Conceptual Framework for Supply Chain Integration}

A number of researchers have found that higher levels of integration generally lead to better performance (Gimenez \& Ventura, 2005; Stock et. al., 1998). Some researchers have used all 
three integration variables in assessing the effect of supply chain integration on performance and found that, SCI directly relates to performance and that internal and external integration influence each other along with performance. However, internal integrations impact on performance depends on the functional areas that are being integrated and the level of external integration (Gimenez \& Ventura, 2005; Stank et. al., 2001; Zhao et. al., 2011). In line with other papers from 2000 onwards discussing SCI and performance, Stock et. al., (2000); Frohlich and Westbrook (2001) found that the levels of integration correlate and influence each other positively. Furthermore, it is difficult to come to a conclusion that integration clearly affects performance, since most of the studies in this field are discernable enough that integration and performance have been defined and measured variously and mostly limited way (FabbeCostes \& Jahre, 2007).

Firms have realized that enhanced competitiveness requires that companies ceaselessly integrate within a network of organizations.

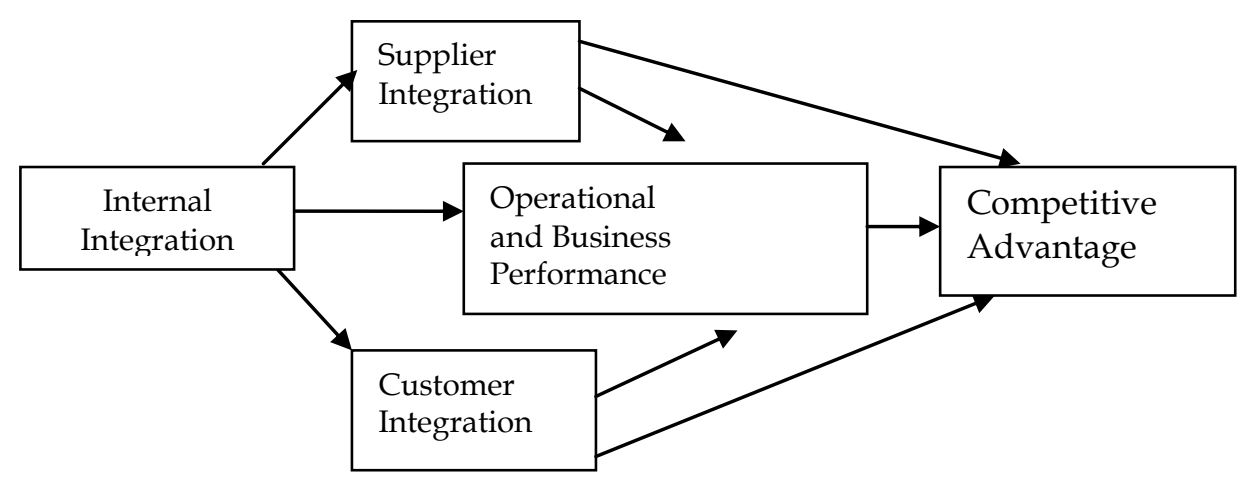

Fig 5.1: Conceptual Framework of SCI

A conceptual framework (as shown in Fig. 5.1 and 5.2) is proposed for integration of supply chain. This model explains that, internal integration leads to external integration and both lead to improved performance and competitive advantage. It is suggested that, future researchers should empirically test this model and validate it. 


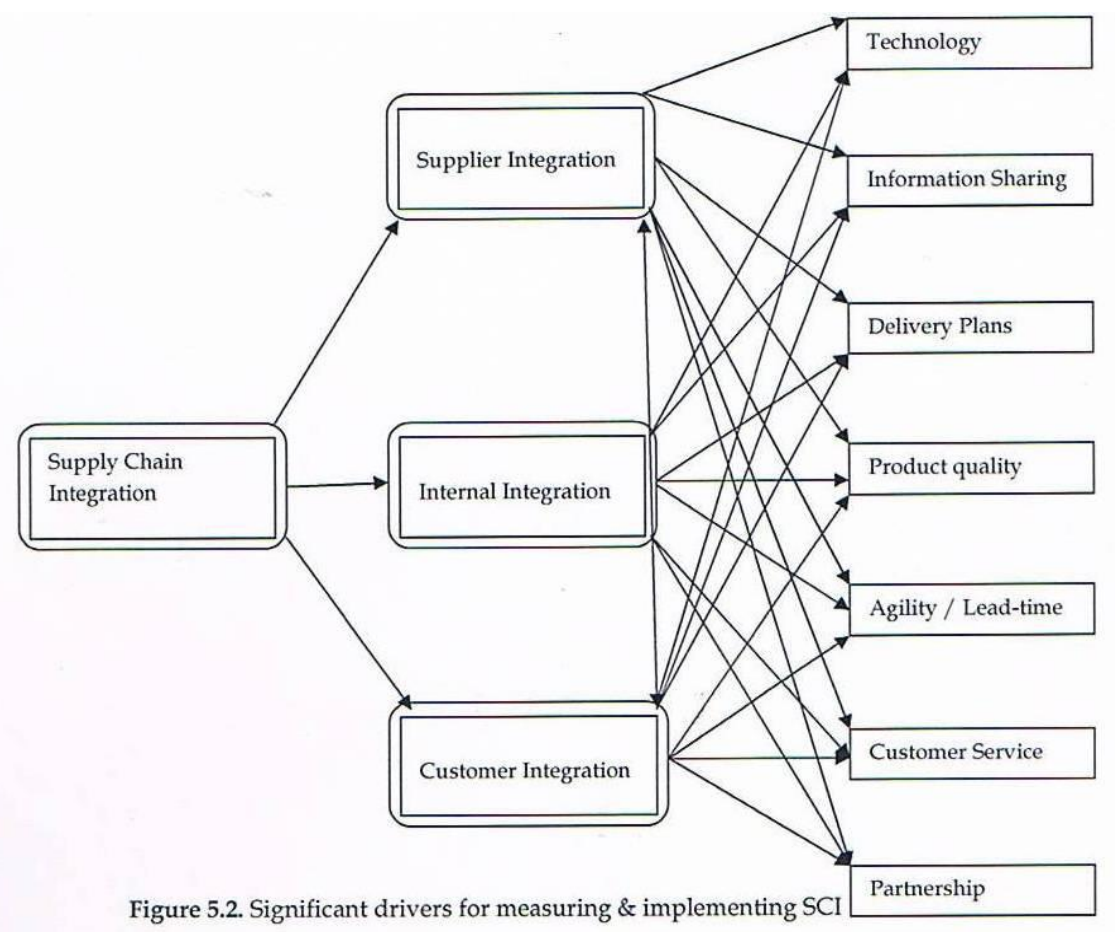

\section{Conclusion}

Supply Chain Management (SCM) is the oversight of materials, information and finances as they move in the whole process from supplier to consumer. SCM involves coordinating and integrating these flows both within and among companies. The efficiency of SCM decides the future of the enterprise and effective SCM has been a focus of many organizations. With the advent of information age, competition between enterprises becomes more and more intense and organizations increasingly find that they must rely on effective supply chains or networks to successfully compete in the global market and networked economy.

The literature review suggests that, the best way of implementing supply chain integration is to start from functional integration through internal to external integrations. Effective implementation of integrated SCM has the potential to generate significant improvements in the performance of firms. Strategic supply chain sustains competitive advantage and encounter integration barriers. 
A conceptual framework/ model designed explain that internal integration leads to external integration and both lead to improved performance and competitive advantage. When a firm develops distinctive supply chain capabilities through supply chain process integration, it is likely to achieve competitive advantage in the market and result in bigger market share.

\section{Scope for future research}

Earlier empirical research in supply chain integration has focused on specific elements of the overall SCM concept rather than on wider cross-functional and inter-organizational integration. This research contributes by identifying the key components to be integrated and thus proposed a model for supply chain integration. Researchers are encouraged to test this model empirically and measure the enhanced performance.

\section{References}

Cohen, S., \& Rousell, J. (2004). Strategic Supply chain management: The five disciplines for top performance. New York: Mc. Graw Hill, pp. 1250.

Fabbe-Costes, N. \&Jahre, M., (2007). Supply chain integration improves performance: The emperor's new suit? The International Journal of Physical Distribution \& Logistics Management, 37 (10), 835-855.

Fawcett, S. E. \& Magnan, G. M., (2002). The rhetoric and reality of supply chain integration. International Journal of Physical Distribution $\mathcal{E}$ Logistics Management, 32(5), 339-361.

Frohlich, M. T., \& Westbrook, R. (2001). Arcs of integration: An international study of supply chain strategies. Journal of Operations Management, 19, 185-200.

Flynn, B. B., Huo, B. \& Zhao, X. (2010). The impact of supply chain integration on performance: $A$ contingency and configuration approach. Journal of Operations Management, 28, 58-71.

Fung, V.(2004), China and the Supply Chain. UPS Longitudes 04, Mapping the New World of Synchronized Commerce.

Gimenez, C., \& Ventura, E. (2005). Logistics-Production, Logisticsmarketing and external integration: Their impact on performance. International Journal of Operations \& Production Management, 25 (1), 2038. 
Handfield, R. B. \& Nichols, E. L., (2002). Key Issues in global supply base management. Industrial Marketing Management, 33 (1), 29-36.

Hussain, A. H. A. \& Nassar, M. O., (2010). Supply Chain Integration: Definition and Challenges. Proceedings of Multinational Conference of Engineers and Computer Scientists, 1, Hong Kong.

Hult, G., Thomsa, M., Ketchen, D.J. Jr\&Slater, S.F. (2004). Information Processing, knowledge development and strategic supply chain performance. Academy of Management Journal, 47 (2), 241-254.

Ireland, R. D. \& Webb, J. W.(2007). A multi-theoretic perspective on trust and power in strategic supply chains.Journal of Operations Management, 25 (2), 482-497.

Kahn, K. A., (1998). Marketing's Integration with other departments. Journal of Business Research., 42 (1), 53- 62.

Kim, S. W., (2006). Effects of Supply Chain Management Practices, Integration and Competitive Capability on Performance. An International Journal, 11 (3), 241-248.

Koufteros, X., Vonderembse, M. \& Jayaram, J., (2005). Internal and external integration for product development:The contingency effects of uncertainty, equivocality and platform strategy. Decision Science, 36 (1), 97-133.

Lambert, M. D., Cooper, C. M. \& Pagh, D. J. (1998). Supply Chain Management: Implementation issues and research opportunities. The International Journal of Logistics Management, 9 (2), 1-2.

Lewin, K. (1951). Iterative triangulation: A theory development process using existing case studies. Journal of Operations Management, 16 (4), 455-469.

Mentzer, J. T., Foggin, J. H. \& Golicic, S. L. (2002). Collaboration: the enablers, impediments and benefits. Supply Chain Management Review, $4(4), 52-58$.

Narasimhan, R. \& Jayaram, J. (1998). Casual linkage in supply chain: An exploratory study of North American manufacturing firms. Decision Sciences, 29 (3), 579-605.

Otchere, A. F., Annan, J. \& Anin, E K., (2013) Achieving Competitive Advantage through Supply Chain Integration in the Cocoa Industry: A case study of Olam Ghana Limited and Produce Buying Company Limited. International Journal of Business and Social Research, 3 (2), 131145.

Pagell, M., (2004). Understanding the factors that enable and inhibit the integration of operations, purchasing and logistics. Journal of Operations Management, 22 (5), 459-487.

Stank, T. P., Keller, S. \& Daugherty, P. J., (2001). Supply Chain collaboration \& logistical service performance. Journal of Business Logistics, 22(1), 29-48. 
Stock, G. N., Greis, N. P. \& Kasarda, J. D., (1998). Logistics, strategy and structure: A conceptual framework. International Journal of Operations and Production Management, 18 (1), 37-52.

Stock, G. N., Greis, N. P. \& Kasadra, J. D., (2000). Enterprise logistics and supply chain structure: The role of fit. International Journal of Operations Management, 18 (5), 531-547.

Stevens, G., (1989). Integrating the supply chain, International Journal of Physical Distribution and Materials Management, 19 (8), 3-8.

Tan K. C. (2001). A framework of supply chain management literature. European journal of purchasing and supply management, 7 (1), 39-48.

Tan, K. C., Kannan, V. R., Hadfield, R. B., (1998). Supply chain management: supplier performance and firmperformance. International Journal of Purchasing and Materials Management, 3, 2-9.

Tutuncu, O. \&, Kucukusta, D., (2008). The role of supply chain management integration in quality management system for hospitals. International Journal of Management Perspectives, 1 (1), 31-39.

Wiengarten, F., Humphreys, P., Guangming, C., Fynes, B. \& McKittrick, A., (2010). Collaborative supply chain practices and performance: Exploring the key role of information quality. Supply Chain Management:An International Journal, 15 (2), 20-36.

Zhao, X., Baofeng, H., Willem, S. \& Jeff Hoi, Y.Y., (2011). The impact of internal integration and relationship commitment on external integration, Journal of Operations Management, 29 (1-2), 17-32.

Zhao, X., Xie, J. \& Zhang, W. J. (2002). The impact of information sharing and ordering co-ordination on supply chain performance. Supply Chain Management: An International Journal, 7 (1), 24-40. 